\title{
Combination of endothelial progenitor cells and BB-94 significantly alleviates brain damage in a mouse model of diabetic ischemic stroke
}

\author{
DAIXUAN ZHOU ${ }^{1 *}$, ZHI HUANG ${ }^{2 *}$, XIAOXI ZHU ${ }^{2}$, TAO HONG $^{3}$ and YUANLI ZHAO ${ }^{4}$
}

${ }^{1}$ Queen Mary College, Nanchang University, Nanchang, Jiangxi 330031; ${ }^{2}$ Key Laboratory of Endemic and Ethnic Diseases, Ministry of Education, Guizhou Medical University, Guiyang, Guizhou 550002; ${ }^{3}$ Department of Neurosurgery, The First Affiliated Hospital of Nanchang University, Nanchang, Jiangxi 330029; ${ }^{4}$ Department of Neurosurgery, Beijing Tiantan Hospital, Capital Medical University, Beijing 100070, P.R. China

Received November 20, 2020; Accepted April 1, 2021

DOI: $10.3892 / \mathrm{etm} .2021 .10221$

\begin{abstract}
Ischemic stroke is a complication of chronic macrovascular disease in type 2 diabetes. However, the pathogenesis of diabetic ischemic stroke has not yet been fully clarified. The aim of the present study was to investigate the underlying effects of endothelial progenitor cells (EPCs) and the matrix metalloproteinase inhibitor BB-94 on diabetic stroke. In vitro experiments were performed using oxygen-glucose deprivation/reoxygenation (OGD/R) model cells, established using HT22 mouse hippocampal cells. MTT assays and flow cytometry revealed that BB-94 prominently induced the proliferation of the OGD/R model cells and prevented their apoptosis. When EPCs and BB-94 were applied to the OGD/R model cells in combination, proliferation was further accelerated and oxidative damage was attenuated. In vivo experiments were also performed using a middle cerebral artery occlusion (MCAO) mouse model. The results of modified neurological severity scoring and oxidative stress marker analysis demonstrated that EPCs and BB-94 prominently alleviated
\end{abstract}

Correspondence to: Professor Tao Hong, Department of Neurosurgery, The First Affiliated Hospital of Nanchang University, 17 Yong Wai Zheng Street, Donghu, Nanchang, Jiangxi 330029, P.R. China

E-mail: ht2000@vip.sina.com

Professor Yuanli Zhao, Department of Neurosurgery, Beijing Tiantan Hospital, Capital Medical University, 119 South Fourth Ring West Road, Fengtai, Beijing 100070, P.R. China

E-mail: zhaoyuanli@pkuih.edu.cn

*Contributed equally

Abbreviations: EPCs, endothelial progenitor cells; VECs, vascular endothelial cells; MMPs, matrix metalloproteinases; ECM, extracellular matrix

Key words: endothelial progenitor cells, BB-94, matrix metalloproteinases, ischemic stroke cerebral ischemia/reperfusion injury in the MCAO model mice. Furthermore, reverse transcription-quantitative PCR and western blot assays revealed that EPCs in combination with BB-94 significantly downregulated the expression of matrix metalloproteinases (MMPs) and upregulated the expression of tissue inhibitor of metalloproteinases 1 in OGD/R cells and MCAO model mice. The results suggest that EPCs were successfully isolated and identified, and the OGD/R cell and MCAO mouse models were successfully established. They also indicate that EPCs alone or in combination with BB-94 may exert protective effects against ischemic stroke via the reduction of MMP expression.

\section{Introduction}

Stroke is an acute cerebral blood circulation disorder, which is the second deadliest and the first most disabling disease worldwide (1). Ischemic stroke accounts for $~ 85 \%$ of cases of stroke, and the main causes of ischemic stroke include middle cerebral artery thrombosis and acute obstruction caused by thrombosis from other sources (2). Diabetes is a group of metabolic diseases characterized by hyperglycemia (3). Sustained hyperglycemia and long-term metabolic disorders can lead to systemic organ and tissue damage, dysfunction and failure (4). Diabetes is also a high-risk factor for ischemic stroke (5). The probability of ischemic stroke in individuals with diabetes is three times higher than that in non-diabetic individuals (6). Furthermore, patients with diabetic stroke have a faster course of disease, higher mortality and worse prognosis than those with other stroke mechanistic subtypes (7). Although there have been numerous studies on different classes of neuroprotectants, including excitatory amino acids, antioxidants, and anti-inflammatory and lipid regulation agents, no drug has been able to exhibit a clear therapeutic effect in clinical practice (8-10). At present, stem cell transplantation is a novel therapeutic strategy for ischemic stroke $(11,12)$. However, research on this therapy for ischemic stroke with diabetes-associated diseases is lacking.

Endothelial progenitor cells (EPCs), as the progenitor cells of endothelial cells, serve essential roles in the repair of 
endothelial injury or dysfunction and the formation of new blood vessels (13). Generally, EPCs are found in the stem cells of bone marrow tissues, and in small amounts in the peripheral blood of healthy organisms (14). When peripheral blood vessels are damaged, EPCs in bone marrow quickly mobilize into the blood circulation under the influence of chemokines and home to the endothelium to assist in the repair of damage due to ischemia, hypoxia or injury (15). EPCs also have the potential to proliferate, and can be directionally differentiated into mature vascular endothelial cells (VECs), or induced to secrete vasogenic growth factors to activate peripheral mature endothelial cells and accelerate the repair of damaged VECs $(16,17)$. EPC transplantation has been demonstrated to be effective in promoting angiogenesis following ischemic stroke in animal models, contributing to the formation of an enriched tubular environment conducive to neurogenesis, thus accelerating the recovery of nerve function (18-20). However, the potential role and mechanism of EPCs in type 2 diabetes with ischemic stroke have not been fully elucidated.

Matrix metalloproteinases (MMPs) are a family of $\mathrm{Zn}^{2+}$-dependent proteases secreted by connective tissues that can degrade components of the extracellular matrix (ECM) (21). Studies have identified that MMPs participate in a variety of biological processes, including the inflammatory response, tumor metastasis and cell migration $(22,23)$. In addition, MMPs and their inhibitors have been demonstrated to be associated with the progression of ischemic stroke and atherosclerosis (24-26). It has been reported that after ischemic stroke, MMPs can disrupt the blood-brain barrier and affect a series of inflammatory cascades (27). Therefore, the targeting of MMPs is considered a potential approach for the treatment of ischemic stroke, and MMP inhibitors may serve as a safe and effective therapy for ischemic stroke.

In the present study, the effects of a combination of EPCs and an MMP inhibitor, BT-94, in diabetic ischemic stroke were explored through a series of in vitro and in vivo experiments.

\section{Materials and methods}

Animals. A total of 32 male C57/BL6 mice weighing 25-30 g were purchased from the Model Animal Research Center of Nanjing University at 6 weeks of age. All mice received free access to food and water for a week at room temperature with a 12-h light/dark cycle and relative humidity of 40-70\% to adapt to the new laboratory environment. For DM mice model, mice fed by high-fat diet (60\% standard diet, $20 \%$ lard, $10 \%$ yolk powder and $10 \%$ saccharose) for 8 weeks and subsequently injected intraperitoneally with $30 \mathrm{mg} / \mathrm{kg}$ STZ. Meanwhile, the other mice sequentially fed with a standard diet for collection EPCs. All experiments using animals were approved by the Institutional Animal Ethics Committee of Guizhou Medical University and conducted according to Animal Care Guidelines for the Care and Use of Animals from Guizhou Medical University.

Isolation and culture of EPCs. Cell culture dishes were coated with fibronectin (Sigma-Aldrich; Merck KGaA) and incubated at $37^{\circ} \mathrm{C}$ for $1 \mathrm{~h}$. Mice were anesthetized using $2 \%$ pentobarbital sodium $(45 \mathrm{mg} / \mathrm{kg}$, intraperitoneal injection; cat. no. 1063180500; Merck KGaA). After sacrificing the mice by cervical dislocation, the limbs were removed and the muscles shaved off to reveal the bones. The bone marrow cavity was exposed and cells were collected from the cavity and rinsed with PBS. The cell suspension was added as an upper layer to $5 \mathrm{ml}$ lymphocyte separation medium (Sigma-Aldrich; Merck KGaA), and density gradient centrifugation $\left(550 \mathrm{x} \mathrm{g}, 20 \mathrm{~min}, 37^{\circ} \mathrm{C}\right)$ was performed until the marrow cavity fluid was divided into four layers. The fog-like white layer, which was the mononuclear cell layer, was gently sucked out using a straw, and the cells were cultured using endothelial growth medium ${ }^{\mathrm{TM}}-2$ (cat. no. CC-3162; Lonza Group, Ltd.) containing 5\% fetal bovine serum (FBS; cat. no. 10099-141; Gibco; Thermo Fisher Scientific, Inc.) at $37^{\circ} \mathrm{C}$ with $5 \% \mathrm{CO}_{2}$. The EPCs were cultured for 7 days for use in the subsequent experiments.

Detection of Dil-labeled acetylated low-density lipoprotein (Dil-ac-LDL) and FITC-lectin-Ulex europaeus agglutin (UEA)-1. After washing the EPCs with PBS three times on day 10 of incubation, the EPCs were cultured in M199 medium (Gibco; Thermo Fisher Scientific, inc.) containing $12 \mu \mathrm{g} / \mathrm{ml}$ Dil-ac-LDL (cat. no. BT-902; Biomedical Technologies; Alfa Aesar) at $37^{\circ} \mathrm{C}$ in an incubator with $5 \% \mathrm{CO}_{2}$ for $4 \mathrm{~h}$. After washing, the EPCs were fixed with $2 \%$ paraformaldehyde for $20 \mathrm{~min}$ at $4^{\circ} \mathrm{C}$ and $10 \mu \mathrm{g} / \mathrm{ml} \mathrm{FITC-lectin-UEA-1}$ (cat. no. L9006; Sigma-Aldrich; Merck KGaA) was added and incubated at $37^{\circ} \mathrm{C}$ for $4 \mathrm{~h}$. After sealing with neutral resin, the labeled cells were observed and images captured using a laser confocal microscope (Olympus Corporation).

Immunofluorescence (IF) assay. EPCs were inoculated in 24-well plates and incubated for 3 days, after which they were washed with PBS to remove any detached cells. Then, adherent cells were fixed with $10 \%$ formalin for $15 \mathrm{~min}$ at room temperature to ensure that the EPCs were completely adherent to the well. The EPCs were blocked using 5\% bovine serum albumin (BSA; Sigma-Aldrich; Merck KGaA) for $1 \mathrm{~h}$ at room temperature and incubated with the following antibodies from Abcam at $4^{\circ} \mathrm{C}$ overnight: Anti-CD34 (1:10,000; rabbit; cat. no. ab81289; Abcam), anti-CD133 (1:2,000; rabbit; cat. no. ab222782; Abcam), anti-VEGFR2 (1:1,000; rabbit; cat. no. ab134191; Abcam) and anti-von Willebrand factor (vWF; 1:1,000; rabbit; cat. no. ab154193; Abcam). The EPCs were then processed with Alexa Fluor ${ }^{\circledR} 488$ antibodies (1:100; cat. no. sc-516248; Santa Cruz Biotechnology, Inc.) for $1 \mathrm{~h}$ at room temperature. After nuclear staining with DAPI (1:500; cat. no. D9564; Sigma-Aldrich; Merck KGaA) at room temperature for $5 \mathrm{~min}$, a fluorescence microscope was used for visualization.

Construction of an oxygen-glucose deprivation/reoxygenation $(O G D / R)$ cell model. HT22 mouse hippocampal cells (cat. no. SCC129; Merck KGaA) were grown in high-glucose DMEM (Gibco; Thermo Fisher Scientific, Inc.) with $10 \%$ FBS, $2 \mathrm{mM}$ glutamine, $100 \mathrm{U} / \mathrm{ml}$ penicillin and $100 \mu \mathrm{g} / \mathrm{ml}$ streptomycin. The OGD/R model was constructed following the protocol described in previous studies (28-31). The HT22 cells were incubated in glucose-free DMEM (Gibco; Thermo Fisher Scientific, Inc.) under hypoxic conditions $\left(1 \% \mathrm{O}_{2}\right.$, $94 \% \mathrm{~N}_{2}, 5 \% \mathrm{CO}_{2}$ ) at $37^{\circ} \mathrm{C}$ for $2 \mathrm{~h}$, and then cultured in normal 
DMEM under normal oxygen conditions (95\% air, $5 \% \mathrm{CO}_{2}$ ) for $24 \mathrm{~h}$. HT22 cells cultured in normal oxygen conditions were used as a control.

Establishment of the middle cerebral artery occlusion (MCAO) model. Based on previous research (32), the aforementioned DM mice were anesthetized by the intraperitoneal injection of $2 \%$ pentobarbital sodium $(45 \mathrm{mg} / \mathrm{kg})$. The common carotid artery, internal carotid artery and external carotid artery were separated, and blood flow to the internal and common carotid arteries was briefly blocked. This was achieved by inserting a heated nylon thread into the bifurcation of the common carotid artery and into the internal carotid artery. The heated nylon wire was quickly advanced to the bifurcation of the internal carotid artery and common carotid artery by $\sim 10 \mathrm{~mm}$ and knotted. The body temperature of the mice was maintained at $37^{\circ} \mathrm{C}$ during the procedure, and the thread plug was removed after $60 \mathrm{~min}$.

Experimental groups. After the DM-MCAO model was established for $24 \mathrm{~h}$, mice were randomly divided into four groups as follows: DM-MCAO model group $(n=8)$; DM-MCAO + EPCs $(n=8)$, in which $1 \times 10^{6}$ EPCs were administered to MCAO model mice through the right internal carotid artery; DM-MCAO + BB-94 (cat. no. S7155; Selleck Chemicals) $(\mathrm{n}=8)$, in which BB-94 $(50 \mathrm{mg} / \mathrm{kg})$ was administered intraperitoneally to MCAO model mice once a day for 7 days; and DM-MCAO + EPCs + BB-94 $(n=8)$.

Modified neurological severity score (mNSS). With reference to a previous study (33), scoring was performed using an 18-point mNSS system to evaluate the neurological function of the mice, where 0 is a normal score, and 18 is the maximal deficit score. The mNSS assessment includes four neurological tests, namely, a fine motor function measurement scale, sensory ability test, beam balance test, and absence of reflection and abnormal motion. Data were analyzed using a Kruskal-Wallis test followed by Steel-Dwass tests to compare between multiple groups.

3-(4,5-Dimethyl-2-thiazolyl)-2,5-diphenyl-2H-tetrazolium bromide (MTT) assay. The OGD/R model cells were collected and adjusted to a concentration of $1 \times 10^{5}$ cells $/ \mathrm{ml}$. Then, $100 \mu 1$ cells/well were inoculated into 96-well plates. Different concentrations of BB-94 $(0,5,10,20,30$ and $40 \mathrm{mM} ; 20 \mu \mathrm{l})$ were added to each well. In another experiment, OGD/R model cells were treated with 1,000 EPCs or/and BB-94 (5 mM). For each group, 6 duplicate wells were set. The cells were cultured for $48 \mathrm{~h}$ at $37^{\circ} \mathrm{C}$. The supernatant was then discarded and $20 \mu \mathrm{l}$ MTT $(10 \mathrm{mg} / \mathrm{ml})$ was added to each well. After $4 \mathrm{~h}$ at $37^{\circ} \mathrm{C}, 150 \mu \mathrm{l}$ dimethyl sulfoxide was added and the plate was oscillated for $10 \mathrm{~min}$. The absorbance value at $490 \mathrm{~nm}$ was measured using a microplate reader.

Flow cytometric analysis. OGD/R cells were collected and incubated with various concentrations of BB-94 $(0,5,10,20$, 30 and $40 \mathrm{mM}$ ) for $48 \mathrm{~h}$. The apoptosis rate in each group was then assessed using Annexin V/FITC double staining with a FACSCalibur Flow Cytometry System (each, BD Biosciences) according to the manufacturer's instructions. The results were analyzed using FlowJo v.8.0 software (Tree Star, Inc.).
Enzyme-linked immunosorbent assays (ELISAs). For assessment of the in vitro experiment, the culture supernatants of OGD/R model cells treated with EPCs or/and BB-94 (5 mM) were collected for analysis; for the in vivo experiment, serum was collected from the MCAO model mice treated with EPCs or/and BB-94 $(50 \mathrm{mg} / \mathrm{kg})$. The aforementioned samples were prepared for ELISA according to the instructions of the ELISA kits. Superoxide dismutase (SOD), reactive oxygen species (ROS), malondialdehyde (MDA) and D-lactate dehydrogenase (D-LDH) were quantified using a mouse SOD ELISA kit (cat. no. E-EL-M2398), ROS Assay kit (cat. no. E-BC-K138), MDA ELISA kit (cat. no. E-EL-0060c) and mouse D-LDH ELISA kit (cat. no E-EL-M0419c), all from Elabscience.

Collection of brain tissue samples. Mice in each group were anesthetized with an intraperitoneal injection of $2 \%$ pentobarbital sodium $(45 \mathrm{mg} / \mathrm{kg})$ and then decapitated. The brain tissues were removed and immediately used for later experiments.

Reverse transcription-quantitative PCR (RT-qPCR) assay. The obtained brain tissues $(20 \mathrm{mg})$ were added to $1 \mathrm{ml}$ TRIzol ${ }^{\circledR}$ reagent (cat. no. 15596026; Thermo Fisher Scientific, Inc.) and the tissues were cut up and ground. Total mRNAs were isolated from the tissues according to the manufacturer's protocol. Total RNA was isolated from the OGD/R model cells also using TRIzol ${ }^{\circledast}$ (Invitrogen; Thermo Fisher Scientific, Inc.) according to the manufacturer's protocol. The purity and content of total RNA were determined by UV spectrophotometry. A Reverse Transcription kit (Takara Bio, Inc.) was used to synthetize cDNA from the RNA according to the manufacturer's protocol. The following temperature protocol was used: $37^{\circ} \mathrm{C}$ for $15 \mathrm{~min}$ (reverse transcription reaction) and $85^{\circ} \mathrm{C}$ for $5 \mathrm{sec}$ (reverse transcriptase inactivation reaction). The levels of MMP-2, MMP-8, MMP-9 and tissue inhibitor of metalloproteinases-1 (TIMP-1) were examined using SYBR-Green PCR Master Mix (Applied Biosystems; Thermo Fisher Scientific, Inc.). The thermocycling conditions for PCR was as follows: $95^{\circ} \mathrm{C}$ for $3 \mathrm{~min}$, followed by 40 cycles of denaturation at $95^{\circ} \mathrm{C}$ for $10 \mathrm{sec}$, followed by annealing and extension at $58^{\circ} \mathrm{C}$ for $30 \mathrm{sec}$. The relative expression level was calculated using the $2^{-\triangle \Delta C q}$ method (34). The primers used are displayed in Table I. GAPDH was used as the reference gene.

Western blot assay. Ground brain tissues (20 $\mathrm{mg})$ were added to RIPA lysis buffer (cat. no. P0013B; Beyotime Institute of Biotechnology) containing protease inhibitor, and total proteins were extracted by centrifugation at $14,000 \mathrm{x}$ g for $10 \mathrm{~min}$ at $4^{\circ} \mathrm{C}$. The OGD/R cells $\left(1 \times 10^{6} /\right.$ well $)$ were washed once with ice cold PBS and lysed with RIPA lysis buffer on ice for $30 \mathrm{~min}$, after which the total protein was also extracted using RIPA lysis buffer (Beyotime Institute of Biotechnology). An Ultra-Bradford Protein Assay kit (Sangon Biotech Co., Ltd.) was used to determine the concentration of proteins. The proteins (30 $\mu \mathrm{g} / \mathrm{lane})$ were subjected to $10 \%$ SDS-PAGE, and then transferred onto a PVDF membrane (Roche Diagnostics). After blocking the PVDF membrane with 5\% BSA for $1 \mathrm{~h}$, the membrane was incubated with primary antibodies overnight at $4^{\circ} \mathrm{C}$. The secondary antibody HRP-labeled goat anti-rabbit IgG (dilution 1:5,000; cat. no. ab6721; Abcam) was then 
Table I. Sequences of primers used in quantitative PCR.

\begin{tabular}{ll}
\hline Gene & \multicolumn{1}{c}{ Sequence (5'-3') } \\
\hline GAPDH & Forward: TGTTCGTCATGGGTGTGAAC \\
GAPDH & Reverse: ATGGCATGGACTGTGGTCAT \\
MMP-2 & Forward: CCCTCCCCTGATGCTGATACT \\
MMP-2 & Reverse: GTCACTGTCCGCCAAATAAACC \\
MMP-8 & Forward: CTGTTGAAGGCCTAGAGCTGCTG \\
& CTCC \\
MMP-8 & Reverse: GATCTTCTCTTCAAACTCT ACCC \\
MMP-9 & Forward: CCCTGGAGACCTGAGAACCA \\
MMP-9 & Reverse: AACCATAGCGGTACAGGTATTCCT \\
TIMP-1 & Forward: CTGGCATCCTCTTGTTGCTATC \\
TIMP-1 & Reverse: AACGCTGGTATAAGGTGGTCTC
\end{tabular}

MMP, matrix metalloproteinase; TIMP-1, tissue inhibitor of metalloproteinases 1 .

applied to react at room temperature for $1 \mathrm{~h}$. After visualization of the bands using an ECL reagent (cat. no. sc-2048; Santa Cruz Biotechnology, Inc.), the results were recorded using a gel imaging system (Kodak film developer; FUJIFILM Wako Pure Chemical Corporation) and analyzed using ImageJ software (version 7.0; National Institutes of Health). The primary antibodies targeted MMP-2 (1:1,000; cat. no. ab97779), MMP-9 (1:1,000; cat. no. ab38898), MMP-8 (1:500; cat. no. ab53017), TIMP-1 (1:1,000; cat. no. ab211926) and GAPDH (1:2,000; cat. no. ab9482), and were all acquired from Abcam.

$H \& E$ staining. After fixing the brain tissues with $4 \%$ paraformaldehyde at $4^{\circ} \mathrm{C}$ overnight, the tissues were dehydrated with gradient ethanol, made transparent with xylene (cat. no. 534056; Sigma-Aldrich; Merck KGaA) and embedded with paraffin. The tissues were then sliced into $3-\mu \mathrm{m}$ slices. After dewaxing, the slices were processed with xylene and gradient ethanol. The sections were stained with hematoxylin (cat. no. HHS32; Sigma-Aldrich; Merck KGaA) for $10 \mathrm{~min}$ at room temperature and then treated with $1 \%$ hydrochloric acid ethanol. After washing, the slices were stained with $0.5 \%$ eosin (cat. no. 6766007; Thermo Fisher Scientific, Inc.) for $5 \mathrm{~min}$ at room temperature, dehydrated with 70, 85, 95 and $100 \%$ ethanol, and made transparent with xylene twice. After treatment with neutral gum, the stained sections were observed under a light microscope.

TUNEL staining. After brain tissues in each group were fixed following the above methods, the sections were dewaxed and tested for apoptosis using a TUNEL assay. The specific procedures for TUNEL staining were performed according to the instructions provided with the TUNEL kit (cat. no. MK1020; Wuhan Boster Biological Technology, Ltd.). TUNEL-positive cells were those with brown granules in the nucleus.

Statistical analysis. All data from the current study are presented as the mean \pm standard deviation based on three repetitions. All results were calculated using GraphPad Prism Software (version Prism 7; GraphPad Software, Inc.).
Differences were analyzed by one-way ANOVA followed by Tukey's post-hoc test. For mNSS analysis, data were analyzed using the Kruskal-Wallis test and Steel-Dwass tests were performed to compare multiple groups. $\mathrm{P}<0.05$ was considered to indicate a statistically significant difference.

\section{Results}

Culture and identification of EPCs. EPCs were isolated from mouse bone marrow via density gradient centrifugation. After 1 and 7 days of incubation, the morphology of the EPCs was observed using a microscope. Following 1 day of culture, the EPCs were round, small and suspended in the medium; however, after 7 days of culture, the number of EPCs was markedly increased, and the cells exhibited fusiform or polygonal morphology, and were adherent to the well (Fig. 1A). The Dil-ac-LDL and FITC-lectin-UEA-1 fluorescent staining results revealed that the cytoplasm of EPCs took up Dil-ac-LDL (red) and the membranes of EPCs bound with FITC-Lectin-UEA-1 (green), suggesting that EPCs were differentiating (Fig. 1B and C). Furthermore, the results of IF staining assays demonstrated the presence of surface markers for EPCs, namely CD34, CD133, VEGFR2 and $v W F$ (Fig. 1D-G). These results indicate that EPCs were successfully isolated from mouse bone marrow.

MMP inhibitor BB-94 accelerates proliferation and prevents apoptosis in OGD/R model cells in a dose-dependent manner. The possible effects of the MMP inhibitor BB-94 in stroke were next investigated. Firstly, an OGD/R cell model was established, and the OGD/R cells were stimulated with $0,5,10$, 20, 30 and 40 mM BB-94 for 48 h. As shown in Fig. 2A, BB-94 significantly increased the proliferation of OGD/R cells, with $20 \mathrm{mM}$ BB-94 exhibiting the strongest effect. The proliferation of the OGD/R cells began to decrease when the BB-94 concentration reached 30 or $40 \mathrm{mM}$. which suggests that high doses of BB-94 might have a certain toxic effect on the proliferating activity of $\mathrm{OGD} / \mathrm{R}$ cells $(\mathrm{P}<0.01)$. Additionally, flow cytometric analysis revealed that cell apoptosis was significantly attenuated in BB-94-treated OGD/R cells compared with untreated $\mathrm{OGD} / \mathrm{R}$ cells $(\mathrm{P}<0.05$; Fig. $2 \mathrm{~B}$ and $\mathrm{C})$. To further analyze the possible effect of BB-94 on MMPs in OGD/R model cells, the OGD/R model cells were treated with 20 mM BB-94 and analyzed using RT-qPCR. The results demonstrated that the expression levels of MMP-2, MMP-9 and MMP-8 were significantly reduced, and the expression of TIMP-1 was significantly increased in BB-94-treated OGD/R cells compared with untreated OGD/R cells $(\mathrm{P}<0.05$; Fig. 2D). Similarly, the western blotting results also showed that BB-94 significantly downregulated MMP-2, MMP-9 and MMP-8 and upregulated TIMP-1 expression in OGD/R cells $(\mathrm{P}<0.01$; Fig. 2E). These results certified that BB-94 exhibited protective effects in OGD/R model cells.

Combined application of EPCs and BB-94 induces proliferation and alleviates oxidative damage in $O G D / R$ model cells. The impacts of EPCs and BB-94 on the proliferation and oxidative damage of $\mathrm{OGD} / \mathrm{R}$ model cells were subsequently investigated. MTT analysis demonstrated that EPCs or BB-94 each significantly facilitated the proliferation 
A

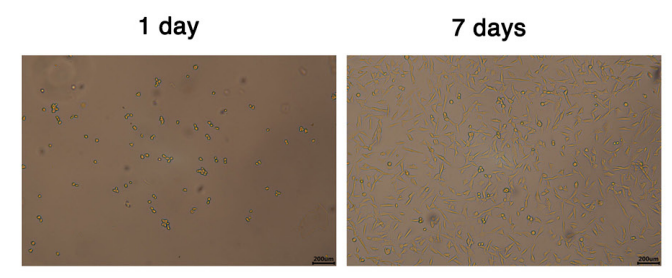

B

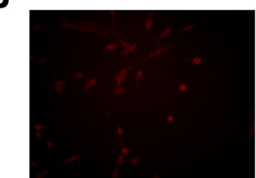

C

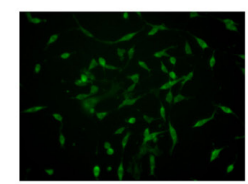

DAPI

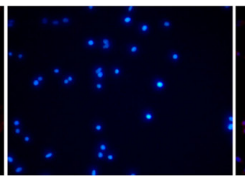

DAPI

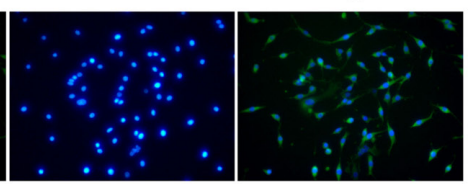

D

CD34

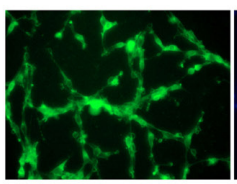

F VEGFR2

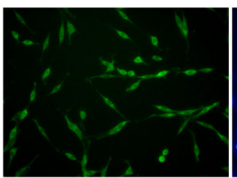

DAPI

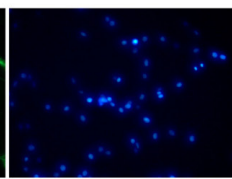

DAPI

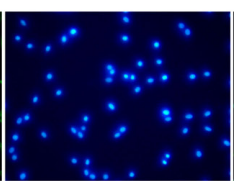

Merged

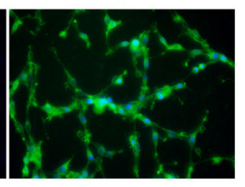

Merged

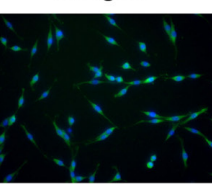

E

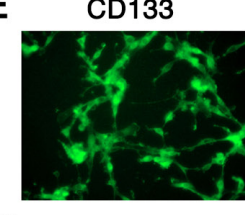

$\mathbf{G}$

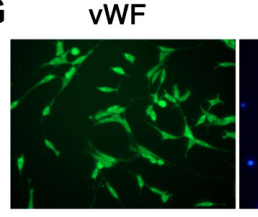

DAPI

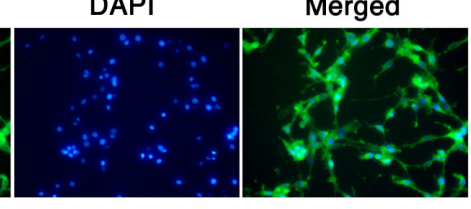

DAPI

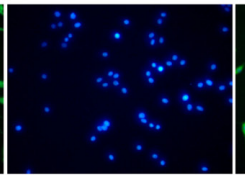

Merged

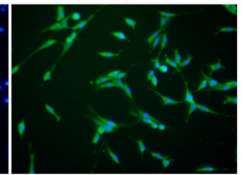

Figure 1. Culture and identification of EPCs. (A) EPCs were isolated from mouse bone marrow by density gradient centrifugation, and the morphology of the cultured EPCs was observed under a microscope after 1 and 7 days (magnification, $\mathrm{x} 200$ ). Fluorescent staining was conducted to identify the abilities of EPCs to (B) take up Dil-ac-LDL and (C) bind UEA-1 (magnification, x200; scale bar, $200 \mu \mathrm{m}$ ). The expression of (D) CD34 (E), CD133, (F) VEGFR2 and (G) vWF was examined using immunofluorescence assays with DAPI nuclear staining (magnification, x200). EPCs, endothelial progenitor cells; Dil-ac-LDL, Dil-labeled acetylated low-density lipoprotein; UEA-1, Ulex europaeus agglutin-1; vWF, von Willebrand factor.

of OGD/R model cells $(\mathrm{P}<0.05)$, and that EPCs used in combination with BB-94 promoted the proliferation of $\mathrm{OGD} / \mathrm{R}$ model cells more strongly than each treatment alone $(\mathrm{P}<0.001$; Fig. 3A). As shown in Fig. 3B, ELISA results revealed that SOD levels were markedly reduced and ROS, MDA and LDH levels were notably elevated in the EPCs or BB-94 groups compared with the control OGD/R group $(\mathrm{P}<0.001)$; furthermore, the combination of EPCs and BB-94 induced a further reduction of SOD levels and significant increases of ROS, MDA and LDH levels $(\mathrm{P}<0.01)$. The impacts of EPCs alone and in combination with BB-94 on MMPs were also studied; EPCs and/or BB-94 were applied to the OGD/R model cells. The levels of MMP-2, MMP-9, MMP-8 and TIMP-1 were determined through RT-qPCR and western blotting. The results showed that MMP-2, MMP-9 MMP-8 expression levels were significantly reduced and TIMP-1 expression was significantly raised in the EPCs or BB-94 groups compared with the control OGD/R group. In addition, compared with the individual treatment groups, the combination of EPCs and BB-94 further downregulated MMP-2, MMP-9 and MMP-8, and upregulated TIMP-1 expression in the OGD/R model cells $(\mathrm{P}<0.05$; Fig. $3 \mathrm{C}$ and $\mathrm{D})$. These results reveal that the combination of BB-94 and EPCs had a significant protective effect on the OGD/R model cells.

EPCs alone and combined with BB-94 prominently attenuate $M C A O$-induced cerebral I/R injury. On the basis of the roles of EPCs and BB-94 in OGD/R model cells, the effects of EPCs and BB-94 on MCAO-induced cerebral I/R injury were further investigated. MCAO model mice were successfully established and the mice were treated with EPCs and/or BB-94. The neurological deficit scores were significantly reduced in the MCAO + EPCs or MCAO + BB-94 groups compared with the control MCAO group, and the combination of EPCs and BB-94 further lowered the neurological deficit scores in the MCAO mice compared with those of mice treated with EPCs or BB-94 alone ( $\mathrm{P}<0.05$; Fig. $4 \mathrm{~A})$. Additionally, H\&E staining revealed that the nerve cells in the brain tissues of MCAO model mice were scattered, and the cells appeared to be loose with evident edema. Treatment with EPCs alone or combined with BB-94 markedly attenuated this abnormal change in the morphological structure of the brain tissues, and this attenuation was most evident in the MCAO rats treated with a combination of EPCs and BB-94 (Fig. 4B). Moreover, through TUNEL analysis, treatment with EPCs or BB-94 alone was found to observably reduce the number of TUNEL-positive cells, and the combined treatment with EPCs and BB-94 further lowered the number of TUNEL-positive cells in the MCAO model mice compared with either EPCs or BB-94 alone (Fig. 4C). These results indicate that EPCs alone and in combination with BB-94 had a marked protective role against cerebral I/R injury in MCAO mice.

EPCs and BB-94 notably alleviate oxidative damage and downregulate MMPs in MCAO model mice. Whether EPCs and BB-94 have an effect on oxidative damage and the expression levels of MMPs/TIMP-1 in MCAO model mice were further determined. The ELISA results indicated that either EPCs or BB-94 alone significantly reduced the SOD concentration and elevated the ROS, MDA and LDH levels in the brain 
A

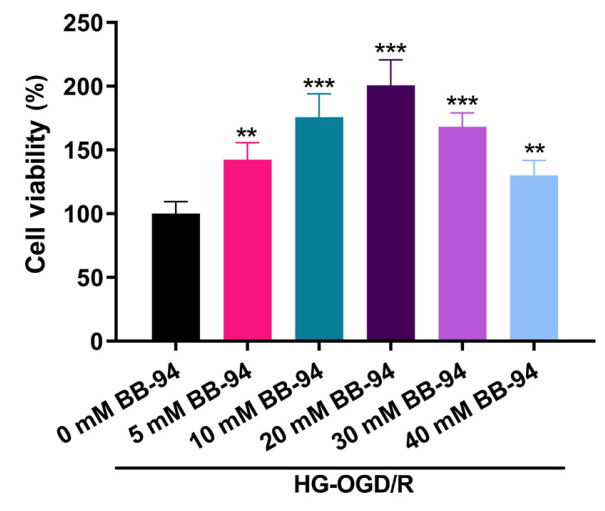

B

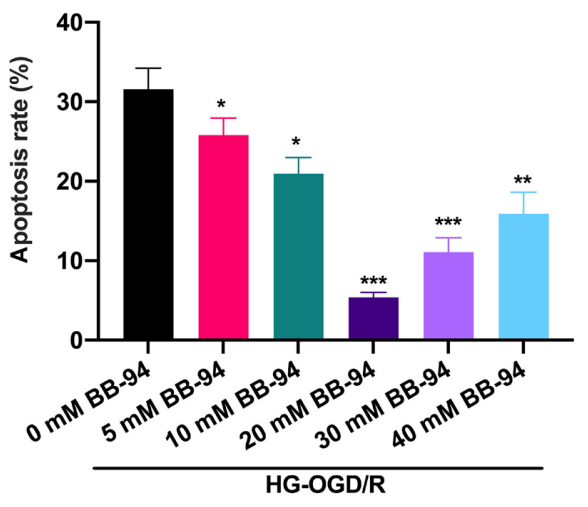

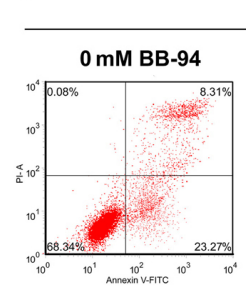

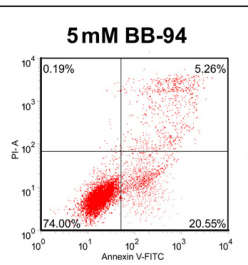

D

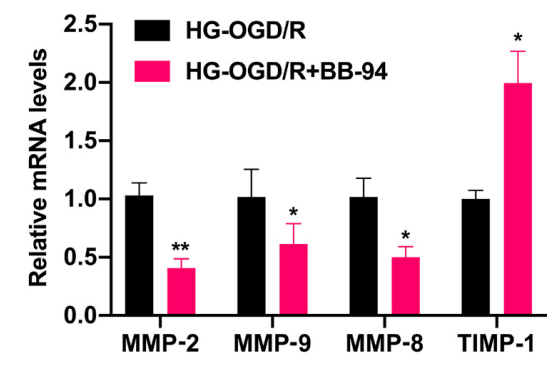

E

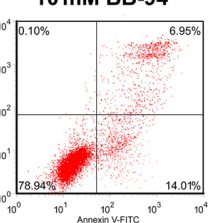
HG-OGD/R

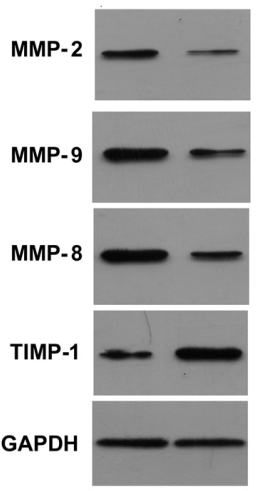

\section{$20 \mathrm{mM}$ BB-94}
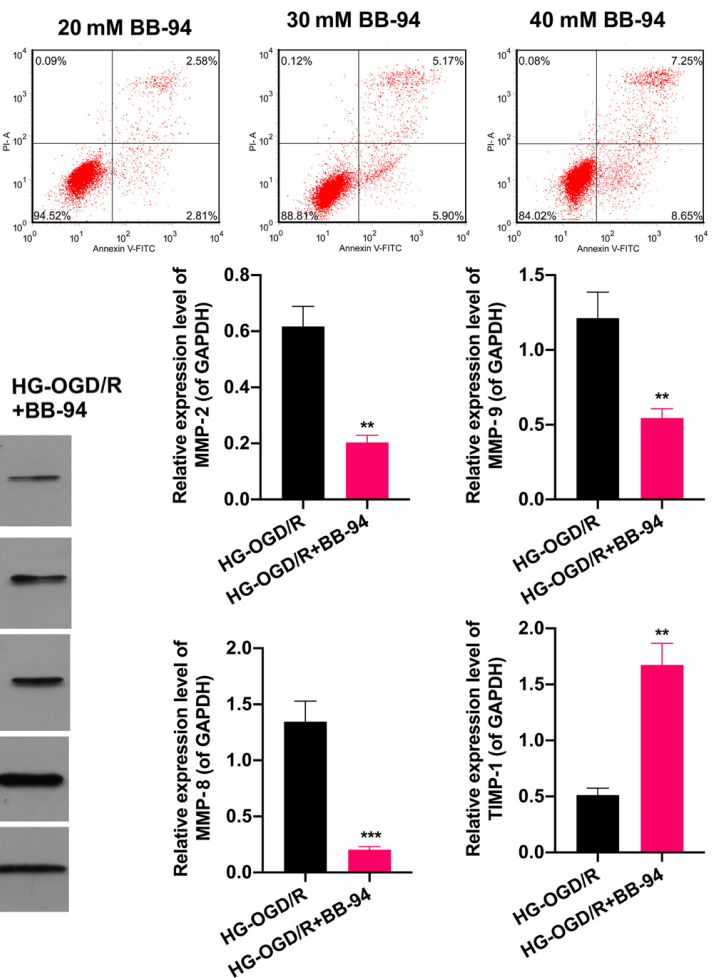

Figure 2. MMP inhibitor BB-94 accelerated the proliferation of OGD/R model cells and prevented their apoptosis. An OGD/R cell model was established, and the cells were stimulated with 0, 5, 10, 20, 30 or 40 mM BB-94 for 48 h. (A) Cell proliferation was evaluated using an MTT assay. (B and C) Flow cytometry was applied to monitor the effect of BB-94 on the apoptosis of the OGD/R cells. (B) The apoptosis rate was calculated and (C) representative flow cytometry plots are shown. ${ }^{*} \mathrm{P}<0.05,{ }^{* *} \mathrm{P}<0.01,{ }^{* * *} \mathrm{P}<0.001$ vs. $0 \mathrm{mM}$ BB-94, (D) OGD/R model cells were treated with $20 \mathrm{mM}$ BB-94, and reverse transcription-quantitative PCR analysis was utilized to examine the levels of MMP-2, MMP-9, MMP-8 and TIMP-1. (E) Western blotting analysis was also performed to evaluate MMP-2, MMP-9, MMP-8 and TIMP-1 expression in the $20 \mathrm{mM} \mathrm{BB}-94$-treated OGD/R cells. ${ }^{*} \mathrm{P}<0.05,{ }^{* *} \mathrm{P}<0.01,{ }^{* * *} \mathrm{P}<0.001$ vs. HG-OGD/HR. MMP, matrix metalloproteinase; HG-, high glucose; OGD/R, oxygen-glucose deprivation/reoxygenation; TIMP-1, tissue inhibitor of metalloproteinases 1.

tissues of the MCAO model mice, and the combined treatment with EPCs and BB-94 further enhanced the effects of EPCs or BB-94 on SOD, ROS, MDA and LDH levels in the mice $(\mathrm{P}<0.001$; Fig. 5A). In addition, RT-qPCR results showed that either EPCs or BB-94 alone markedly downregulated MMP-2, MMP-9 and MMP-8 and upregulated TIMP-1 expression, and the changes in the expression of these genes in the brain tissues of the MCAO model mice were further enhanced when EPCs and BB-94 were used in combination ( $\mathrm{P}<0.05$; Fig. 5B). In addition, the western blot results exhibited the same trends as the RT-qPCR results $(\mathrm{P}<0.05$; Fig. $5 \mathrm{C})$. These results indicate that EPCs alone and combined with BB-94 significantly inhibited oxidative damage and the expression of MMPs in MCAO model mice.

\section{Discussion}

Diabetes is an independent risk factors for stroke, and the mortality rate from cerebrovascular complications in patient with diabetes is 2-4-fold higher than that in non-diabetic individuals (35). The onset time of stroke in patients with type 2 diabetes is 10 years earlier than that in non-diabetic individuals (36). The main pathological changes observed in patients with diabetes and ischemic stroke include macrovascular and microvascular diseases (37). The pathogenesis of diabetic stroke mainly includes fat and lipoprotein metabolic disorders, insulin resistance, hypertension, endothelium-dependent vasomotor dysfunction, microvascular lesions and genetic changes $(38,39)$. Studies have demonstrated that EPCs have significant effects 
A

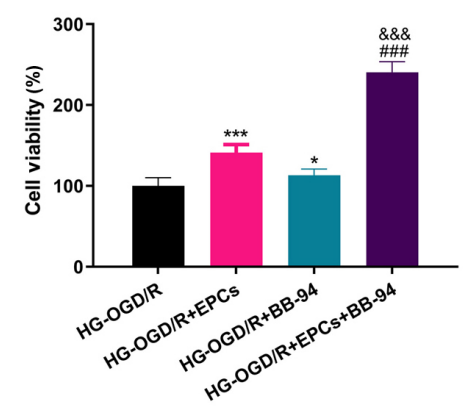

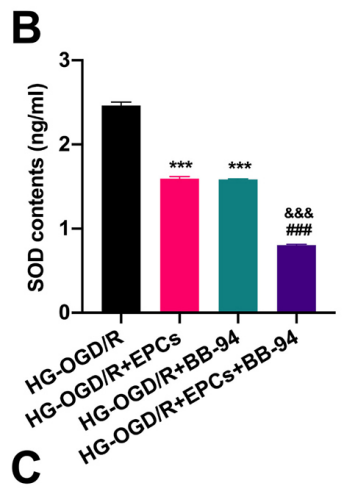
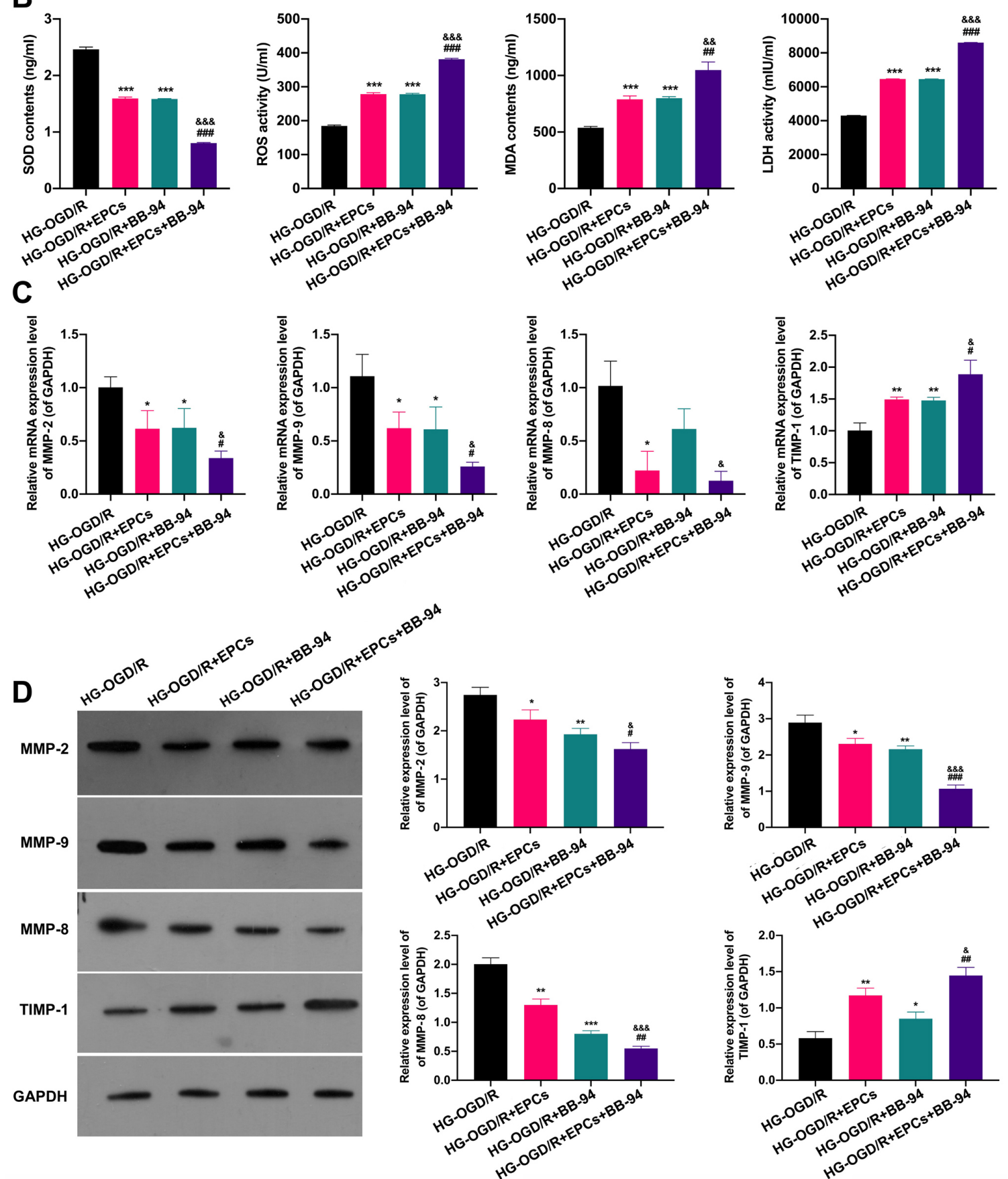

Figure 3. Combined application of EPCs and BB-94 induces proliferation and alleviates oxidative damage in OGD/R model cells. (A) OGD/R model cells were treated with EPCs or/and BB-94 (5 mM) and an MTT assay was used to evaluate the proliferation of the cells. (B) The levels of SOD, ROS, MDA and LDH were assessed using ELISAs. (C) The mRNA expression levels of MMP-2, MMP-9, MMP-8 and TIMP-1 were confirmed by reverse transcription-quantitative PCR in OGD/R cells treated with EPCs and/or 5 mM BB-94. (D) MMP-2, MMP-9, MMP-8 and TIMP-1 protein levels were certified through western blotting analysis in $\mathrm{OGD} / \mathrm{R}$ cells following treatment with EPCs and/or $5 \mathrm{mM}$ BB-94. ${ }^{*} \mathrm{P}<0.05,{ }^{* *} \mathrm{P}<0.01,{ }^{* * * *} \mathrm{P}<0.001$ vs. the OGD/R group; ${ }^{*} \mathrm{P}<0.05$, ${ }^{\# \#} \mathrm{P}<0.01$,

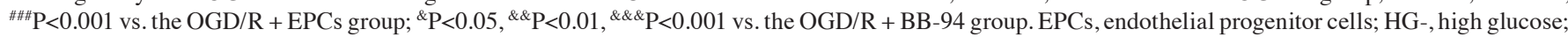
OGD/R, oxygen-glucose deprivation/reoxygenation; SOD, superoxide dismutase; ROS, reactive oxygen species; MDA, malondialdehyde; LDH, lactate dehydrogenase; MMP, matrix metalloproteinase; TIMP-1, tissue inhibitor of metalloproteinases 1. 
A

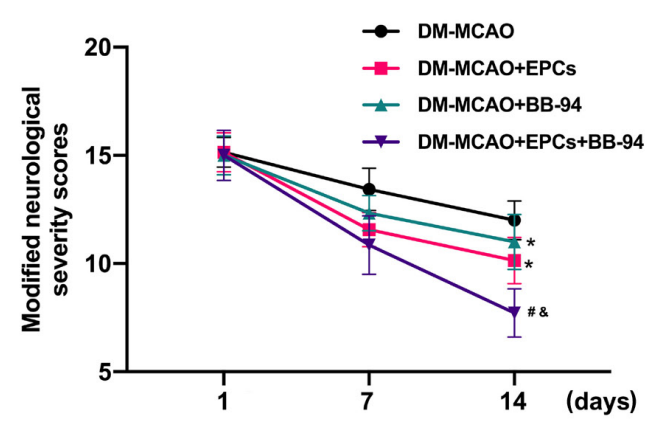

B

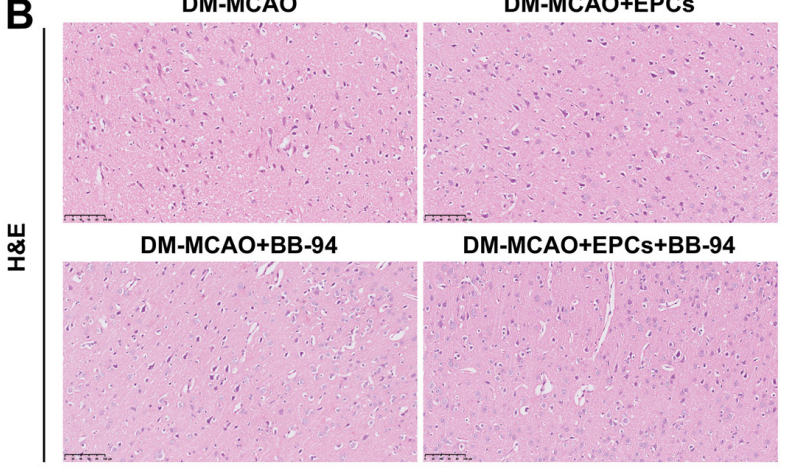

C DM-MCAO DM-MCAO+EPCs

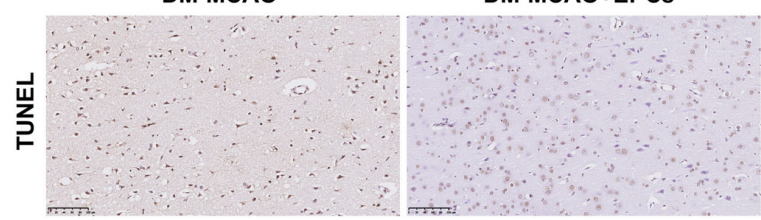

DM-MCAO+BB-94

DM-MCAO+EPCs+BB-94

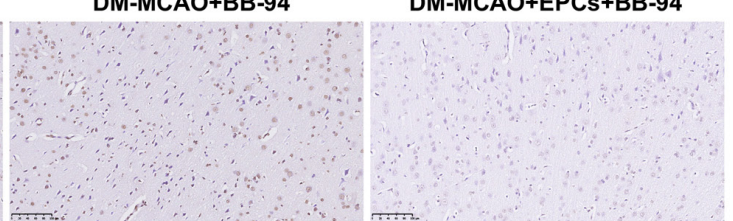

Figure 4. EPCs alone and combined with BB-94 prominently attenuate MCAO-induced cerebral I/R injury. MCAO mice models were established, and the mice were treated with EPCs and/or BB-94. (A) Modified neurological severity scores were applied to assess the neurological deficit of the mice 7 and 14 days after the surgery $(\mathrm{n}=8) .{ }^{*} \mathrm{P}<0.05$ vs. the $\mathrm{MCAO}$ group; ${ }^{\#} \mathrm{P}<0.05$ vs. the $\mathrm{MCAO}+\mathrm{EPCs}$ group; ${ }^{\circledR} \mathrm{P}<0.05$ vs. the $\mathrm{MCAO}+\mathrm{BB}-94$ group. $(\mathrm{B}) \mathrm{After}$ treatment with EPCs and/or BB-94, the morphological structure of brain tissues was evaluated using H\&E staining (magnification, x100; scale bar, 100 $\mu$ m). (C) TUNEL assay was performed to monitor the apoptosis of cells in the brain tissue (magnification, x100; scale bar, $100 \mu \mathrm{m}$ ). EPCs, endothelial progenitor cells; MCAO, middle cerebral artery occlusion; DM, diabetes mellitus.

on vascular repair $(17,40)$. In diabetic retinopathy, EPCs have been shown to contribute to the remodeling of blood vessels by participating in the formation of vascular structures, thereby increasing the normal functioning of vascular systems $(41,42)$. However, diabetes can reduce the number and function of EPCs (43). Traditionally, EPCs are isolated from the bone marrow and are verified as EPCs by testing for the presence of specific surface markers $(44,45)$. CD133 and CD34 are known as markers for hematopoietic stem cells and they are gradually lost during the differentiation and maturation of EPCs (46). VEGFR2 is also a specific marker for endothelial cells. Therefore, CD $34^{+} \mathrm{CD} 113^{+} \mathrm{VEGFR}^{+}$expressing cells are generally identified as EPCs (47). Moreover, endothelial cells produce $\mathrm{vWF}$ in the cytoplasm and specifically take up Dil-ac-LDL and UEA-1, which can also serve as specific markers for endothelial identification $(48,49)$. In the present study, EPCs were extracted from the bone marrow cavities of mice, and the successful extraction of EPCs was demonstrated through measurements of Dil-ac-LDL and UEA-1 uptake, and CD34, CD133, VEGFR2 and vWF expression. In addition, an OGD/R cell model and MCAO mouse model were successfully established.

MMPs are a family of metal-dependent proteolytic enzymes with similar structures and common biochemical properties (50). The ECM is the main component of the vascular wall (51). Research has shown that MMPs are able to degrade all ECM components, with the exception of polysaccharides such as collagen and elastin, and are key enzymes in the extracellular degradation of ECM (52). MMPs and TIMPs together constitute a vital system for regulating the dynamic balance of the ECM (53). In this system, MMP-9 is a widely studied and active MMP, and TIMP-1 is a specific inhibitor of MMP-9 (54). MMP-2 is a key enzyme involved in substrate degradation, and can specifically degrade the main components of the basal membrane of the arterial walls $(55,56)$. Diabetes mellitus (DM) is a chronic disease comprising lifestyle-associated insulin resistance and/or abnormal insulin secretion. Previous studies have shown that an increase in insulin-secreting pancreatic islet $\beta$-cells is a common feature of DM progression $(57,58)$. Recent studies have shown that increased MMPs contribute to the progression of DM by inhibiting islet $\beta$-cell apoptosis through an integrin-mediated Akt/BAD pathway $(59,60)$. Other studies have revealed that the high expression of MMP-9 is associated with poor prognosis and recovery for ischemic stroke $(61,62)$; MMP-8 has a close association with ischemic stroke (26); and MMP-2 polymorphism is associated with the occurrence risk of stroke (63). However, the impacts of MMPs on the progression of diabetic ischemic stroke have not been fully elucidated.

BB-94 is a synthetic MMP inhibitor (64). It has a competitive inhibitory effect on MMPs due the similarity of its chemical structure with that of MMP enzyme restriction sites (65). Previous studies have reported the ability of BB-94 to inhibit multiple disease processes (66), including pancreatitis (67), abdominal aortic aneurysm (64), glioblastoma (68) and breast cancer (69). It has also been shown that BB-94 does not directly affect the viability of cancer cells; instead, it reduces the release of collagenase from these cells (70). Furthermore, acute and long-term toxicological experiments indicate that BB-94 has no toxic effects on animals (71). Despite BB-94 having shown strong promising preclinical data, it failed its phase I trial due to unforeseen side effects (72). This was likely due to the poor solubility of BB-94, which resulted in local toxicity associated with a high dose of the drug administered intraperitoneally (71). Consistent with this, the results of the present study revealed that the proliferation of OGD/R cells was inhibited when the concentration of BB-94 increased to 

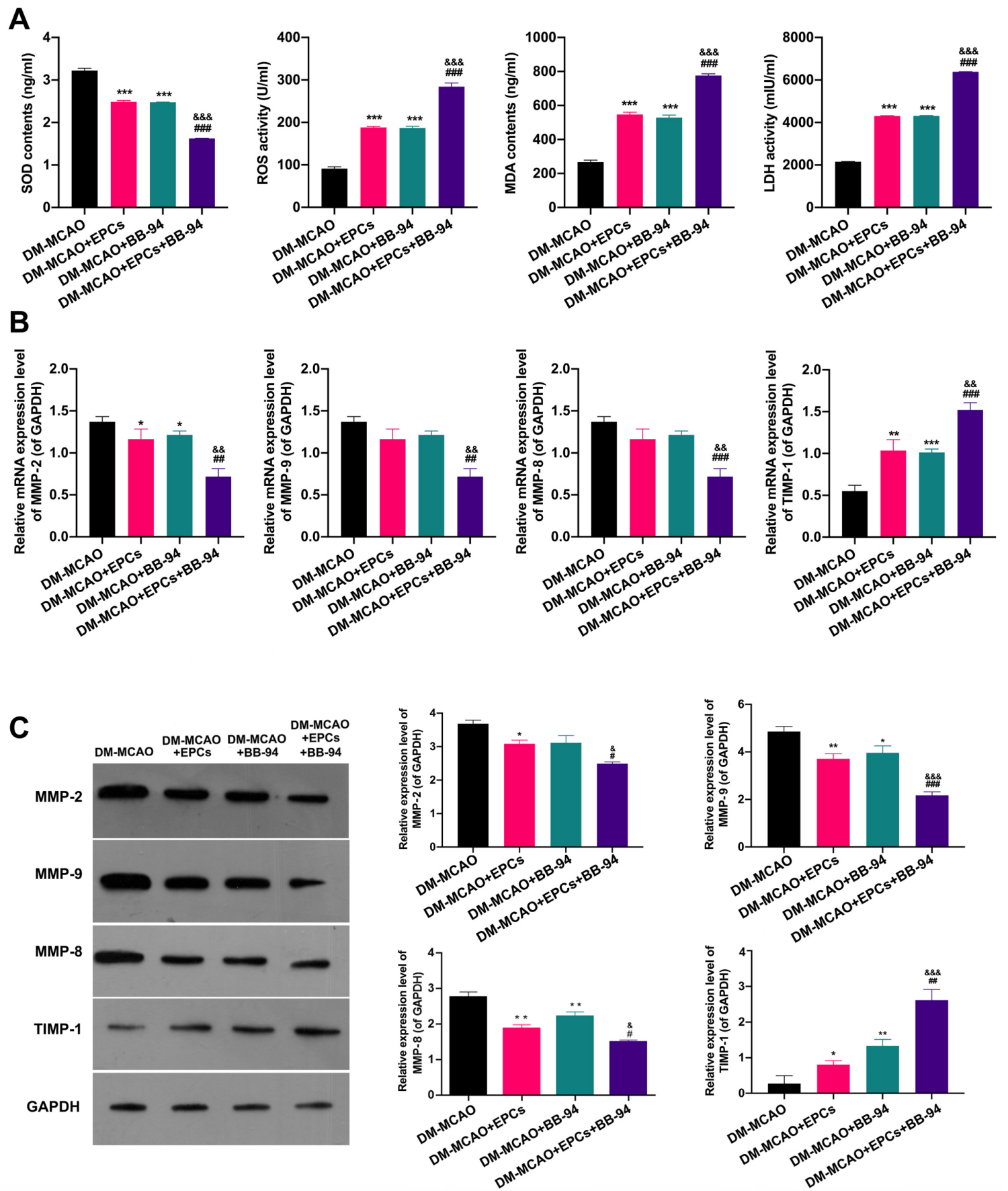

Figure 5. EPCs and BB-94 notably alleviate oxidative damage and downregulate MMPs in MCAO model mice. (A) ELISAs were used to determine the changes of SOD, ROS, MDA and LDH levels in MCAO model mice treated with EPCs and/or BB-94. After treating the mice with EPCs and/or BB-94, MMP-2, MMP-9, MMP-8 and TIMP-1 expression levels were confirmed in the brains of the mice using (B) reverse transcription-quantitative PCR and (C) western blotting. GAPDH served as an internal control. ${ }^{*} \mathrm{P}<0.05,{ }^{* *} \mathrm{P}<0.01,{ }^{* * * *} \mathrm{P}<0.001$ vs. the MCAO group; ${ }^{\# \mathrm{P}}<0.05,{ }^{\# \#} \mathrm{P}<0.01,{ }^{\# \# \#} \mathrm{P}<0.001$ vs. the MCAO + EPCs group; ${ }^{\&} \mathrm{P}<0.05$, ${ }^{\&} \mathrm{P}<0.01,{ }^{\&} \& \& \mathrm{P}<0.001$ vs. the MCAO + BB-94 group. EPCs, endothelial progenitor cells; MMP, matrix metalloproteinase; DM-, diabetes mellitus; MCAO, middle cerebral artery occlusion; SOD, superoxide dismutase; ROS, reactive oxygen species; MDA, malondialdehyde; LDH, lactate dehydrogenase; TIMP-1, tissue inhibitor of metalloproteinases 1.

$\geq 30 \mathrm{mM}$, which indicates that high doses of BB-94 may have a toxic effect on cells. Moreover, the present study showed that BB-94 significantly induced the proliferation of OGD/R model cells, and also inhibited their apoptosis. It also revealed the ability of BB-94 to markedly downregulate MMP-2, MMP-9 and MMP-8, and upregulate TIMP-1 expression in OGD/R model cells.

The present study demonstrated that the combined application of EPCs and BB-94 prominently accelerated the proliferation of $\mathrm{OGD} / \mathrm{R}$ model cells and alleviated oxidative damage in these cells. It also certified that EPCs and BB-94 significantly alleviated cerebral I/R injury in MCAO model mice, and markedly reduced oxidative damage and the expression of certain MMPs in these mice. These results suggest that EPCs can change the dynamic balance of the ECM, and indicate that the combined application of EPCs and BB-94 significantly ameliorated the brain damage induced by diabetic ischemic stroke. 
In summary, the present study successfully isolated and identified EPCs from mice, and established an OGD/R cell model and MCAO mice model. Using these models, the study demonstrated that EPCs alone or combined with BB-94 have protective effects against ischemic stroke that are associated with the reduction of MMP expression.

\section{Acknowledgements}

Not applicable.

\section{Funding}

This study was supported by the National Natural Science Foundation of China (grant. no. 81860321). The funding body played a role in the design of the study and editing the manuscript.

\section{Availability of data and materials}

The datasets used and/or analyzed during the current study are available from the corresponding author on reasonable request.

\section{Authors' contributions}

DZ, ZH and TH designed and performed the experiments; DZ, $\mathrm{ZH}, \mathrm{XZ}$ and $\mathrm{YZ}$ performed the literature research, research design and manuscript editing. TH performed manuscript editing. DZ and $\mathrm{ZH}$ confirm the authenticity of all the raw data. All authors read and approved the final manuscript.

\section{Ethics approval and consent to participate}

This experiments involving animal were approved by the Institutional Animal Ethics Committee of Guizhou Medical University and performed according to Animal Care Guidelines for the Care and Use of Animals from Guizhou Medical University.

\section{Patient consent for publication}

Not applicable.

\section{Competing interests}

The authors declare that they have no competing interests.

\section{References}

1. Guzik A and Bushnell C: Stroke epidemiology and risk factor management. Continuum (Minneap Minn) 23: 15-39, 2017.

2. Randolph SA: Ischemic stroke. Workplace Health Saf 64: 444, 2016.

3. Sreedharan R and Abdelmalak B: Diabetes mellitus: Preoperative concerns and evaluation. Anesthesiol Clin 36: 581-597, 2018.

4. Echouffo-Tcheugui JB and Garg R: Management of hyperglycemia and diabetes in the emergency department. Curr Diab Rep 17: 56, 2017.

5. Hill MD: Stroke and diabetes mellitus. Handb Clin Neurol 126: 167-174, 2014

6. Shindo A and Tomimoto H: Diabetes and ischemic stroke. Brain Nerve 66: 107-119, 2014 (In Japanese)

7. Chen R, Ovbiagele B and Feng W: Diabetes and stroke: Epidemiology, pathophysiology, pharmaceuticals and outcomes Am J Med Sci 351: 380-386, 2016
8. Campos AC, Fogaca MV, Sonego AB and Guimaraes FS: Cannabidiol, neuroprotection and neuropsychiatric disorders. Pharmacol Res 112: 119-127, 2016.

9. Lavaur J, Le Nogue D, Lemaire M,Pype J, Farjot G, Hirsch EC and Michel PP: The noble gas xenon provides protection and trophic stimulation to midbrain dopamine neurons. J Neurochem 142: 14-28, 2017

10. Lavaur J, Lemaire M, Pype J, Nogue DL, Hirsch EC and Michel PP: Xenon-Mediated neuroprotection in response to sustained, low-level excitotoxic stress. Cell Death Discov 2: 16018, 2016.

11. Bernstock JD, Peruzzotti-Jametti L, Ye D, Gessler FA, Maric D, Vicario N, Lee YJ, Pluchino S and Hallenbeck JM: Neural stem cell transplantation in ischemic stroke: A role for preconditioning and cellular engineering. J Cereb Blood Flow Metab 37: 2314-2319, 2017.

12. Boncoraglio GB, Ranieri M, Bersano A, Parati EA and Del Giovane C: Stem cell transplantation for ischemic stroke. Cochrane Database Syst Rev 5: CD007231, 2019.

13. Chong MS, Ng WK and Chan JK: Concise review: Endothelial progenitor cells in regenerative medicine: Applications and challenges. Stem Cells Transl Med 5: 530-538, 2016.

14. Yang JX, Pan YY, Wang XX, Qiu YG and Mao W: Endothelial progenitor cells in age-related vascular remodeling. Cell Transplant 27: 786-795, 2018.

15. Emontzpohl C, Simons D, Kraemer S, Goetzenich A, Marx G, Bernhagen J and Stoppe C: Isolation of endothelial progenitor cells from healthy volunteers and their migratory potential influenced by serum samples after cardiac surgery. J Vis Exp 14: 55192, 2017.

16. Guerra G, Perrotta F and Testa G: Circulating endothelial progenitor cells biology and regenerative medicine in pulmonary vascular diseases. Curr Pharm Biotechnol 19: 700-707, 2018.

17. Rana D, Kumar A and Sharma S: Endothelial progenitor cells as molecular targets in vascular senescence and repair. Curr Stem Cell Res Ther 13: 438-446, 2018.

18. Esquiva G, Grayston A and Rosell A: Revascularization and endothelial progenitor cells in stroke. Am J Physiol Cell Physiol 315: C664-C674, 2018.

19. Li Y, Chang S, Li W, Tang G, Ma Y, Liu Y, Yuan F, Zhang Z, Yang GY and Wang Y: cxcl12-Engineered endothelial progenitor cells enhance neurogenesis and angiogenesis after ischemic brain injury in mice. Stem Cell Res Ther 9: 139, 2018.

20. Ma F, Morancho A, Montaner J and Rosell A: Endothelial progenitor cells and revascularization following stroke. Brain Res 1623: 150-159, 2015.

21. Jablonska-Trypuc A, Matejczyk M and Rosochacki S: Matrix metalloproteinases (MMPs), the main extracellular matrix (ECM) enzymes in collagen degradation, as a target for anticancer drugs. J Enzyme Inhib Med Chem 31: 177-183, 2016.

22. Omran OM and Thabet M: Gelatinases a and B expression in human colorectal cancer in upper egypt: A clinicopathological study. Ultrastruct Pathol 36: 108-116, 2012.

23. Cui N, Hu M and Khalil RA: Biochemical and biological attributes of matrix metalloproteinases. Prog Mol Biol Transl Sci 147: 1-73, 2017.

24. Back M, Ketelhuth DF and Agewall S: Matrix metalloproteinases in atherothrombosis. Prog Cardiovasc Dis 52: 410-428, 2010.

25. Lin HF, His E, Huang LC, Liao YC, Juo SH and Lin RT: Methylation in the matrix metalloproteinase-2 gene is associated with cerebral ischemic stroke. J Investig Med 65: 794-799, 2017.

26. Palm F, Pussinen PJ, Safer A, Tervahartiala T, Sorsa T, Urbanek C, Becher $\mathrm{H}$ and Grau AJ: Serum matrix metalloproteinase-8, tissue inhibitor of metalloproteinase and myeloperoxidase in ischemic stroke. Atherosclerosis 271: 9-14, 2018.

27. Chaturvedi M and Kaczmarek L: Mmp-9 inhibition: A therapeutic strategy in ischemic stroke. Mol Neurobiol 49: 563-573, 2014.

28. Tasca CI, Dal-Cim T and Cimarosti H: In vitro oxygen-glucose deprivation to study ischemic cell death. Methods Mol Biol 125: 197-210, 2015.

29. Liang X, Liu X, Lu F, Zhang Y, Jiang X and Ferriero DM: HIF1a signaling in the endogenous protective responses after neonatal brain hypoxia-ischemia. Dev Neurosci 40: 617-626, 2018.

30. Novak AE, Jones SM and Elliott JP: Induction of the HIF pathway: Differential regulation by chemical hypoxia and oxygen glucose deprivation. bioRxiv: 525006, 2019.

31. Zhang Y, Liu D, Hu H, Zhang P, Xie R and Cui W: HIF-1 $\alpha /$ BNIP3 signaling pathway-induced-autophagy plays protective role during myocardial ischemia-reperfusion injury. Biomed Pharmacother 120: 109464, 2019. 
32. Liu C, Kong X, Wu X, Wang X, Guan H, Wang H, Wang L, Jin $\mathrm{X}$ and Yuan H: Alleviation of A disintegrin and metalloprotease 10 (ADAM10) on thromboangiitis obliterans involves the HMGB1/RAGE/ NF-kappaB pathway. Biochem Biophys Res Commun 505: 282-289, 2018.

33. Chen J,Li Y, Wang L,Zhang Z,Lu D,Lu M and Chopp M: Therapeutic benefit of intravenous administration of bone marrow stromal cells after cerebral ischemia in rats. Stroke 32: 1005-1011, 2001.

34. Lee YK and Lee JA: Role of the mammalian ATG8/LC3 family in autophagy: Differential and compensatory roles in the spatiotemporal regulation of autophagy. BMB Rep 49: 424-430, 2016.

35. Hardigan T, Ward R and Ergul A: Cerebrovascular complications of diabetes: Focus on cognitive dysfunction. Clin Sci (Lond) 130 $1807-1822,2016$

36. Khan S, Shafique L and Miah M: Risk factors and patterns of stroke among diabetic and non-diabetic patients. Imperial Journal of Interdisciplinary Research 3, 2017.

37. Mohammedi K, Woodward M, Hirakawa Y, Zoungas S, Williams B, Lisheng L, Rodgers A, Mancia G, Neal B Harrap S, et al: Microvascular and macrovascular disease and risk for major peripheral arterial disease in patients with type 2 diabetes. Diabetes Care 39: 1796-1803, 2016.

38. Alloubani A, Saleh A and Abdelhafiz I: Hypertension and diabetes mellitus as a predictive risk factors for stroke. Diabetes Metab Syndr 12: 577-584, 2018.

39. Boehme AK, Esenwa $C$ and Elkind MS: Stroke risk factors, genetics, and prevention. Circ Res 120: 472-495, 2017.

40. Rodriguez-Carrio J, Lopez P and Suarez A: Endothelial progenitor cells as mediators of the crosstalk between vascular repair and immunity: Lessons from systemic autoimmune diseases. Curr Med Chem 25: 4478-4496, 2018

41. Lois N, McCarter RV, O'Neill C, Medina RJ and Stitt AW: Endothelial progenitor cells in diabetic retinopathy. Front Endocrinol (Lausanne) 5: 44, 2014.

42. Shao Y, Li X, Wood JW and Ma JX: Mitochondrial dysfunctions, endothelial progenitor cells and diabetic retinopathy. J Diabetes Complications 32: 966-973, 2018.

43. Wils J,Favre J and Bellien J: Modulating putative endothelial progenitor cells for the treatment of endothelial dysfunction and cardiovascular complications in diabetes. Pharmacol Ther 170: 98-115, 2017

44. Schmeisser A, Garlichs CD, Zhang H, Eskafi S, Graffy C, Ludwig J, Strasser RH and Daniel WG: Monocytes coexpress endothelial and macrophagocytic lineage markers and form cord-like structures in matrigel under angiogenic conditions. Cardiovasc Res 49: 671-680, 2001

45. Peichev M, Naiyer AJ, Pereira D, Zhu Z, Lane WJ, Williams M, Oz MC, Hicklin DJ, Witte L, Moore MA and Rafii S: Expression of VEGFR-2 and AC133 by circulating human CD34(+) cells identifies a population of functional endothelial precursors Blood 95: 952-958, 2000.

46. Takahashi T, Kalka C, Masuda H, Chen D, Silver M, Kearney M, Magner M, Isner JM and Asahara T: Ischemia- and cytokine-induced mobilization of bone marrow-derived endothelial progenitor cells for neovascularization. Nat Med 5: 434-438, 1999.

47. He S, Pant D, Schiffmacher A, Bischoff S, Melican D, Gavin W and Keefer C: Developmental expression of pluripotency determining factors in caprine embryos: Novel pattern of NANOG protein localization in the nucleolus. Mol Reprod Dev 73: 1512-1522, 2006.

48. Wagner DD, Olmsted JB and Marder VJ: Immunolocalization of von Willebrand protein in Weibel-Palade bodies of human endothelial cells. J Cell Biol 95: 355-360, 1982.

49. Heeschen C, Aicher A, Lehmann R, Fichtlscherer S, Vasa M, Urbich C, Mildner-Rihm C, Martin H, Zeiher AM and Dimmeler S: Erythropoietin is a potent physiologic stimulus for endothelial progenitor cell mobilization. Blood 102: 1340-1346, 2003.

50. Nagase H, Visse R and Murphy G: Structure and function of matrix metalloproteinases and TIMPs. Cardiovasc Res 69 $562-573,2006$

51. Theocharis AD, Skandalis SS, Gialeli C and Karamanos NK Extracellular matrix structure. Adv Drug Deliv Rev 97: 4-27, 2016

52. Bonnans C, Chou J and Werb Z: Remodelling the extracellular matrix in development and disease. Nat Rev Mol Cell Biol 15: 786-801, 2014

53. Paiva KBS and Granjeiro JM: Matrix metalloproteinases in bone resorption, remodeling, and repair. Prog Mol Biol Transl Sci 148: 203-303, 2017

54. Wei H, Wang S, Zhen L, Yang Q, Wu Z, Lei X, Lv J, Xiong L and Xue R: Resveratrol attenuates the blood-brain barrier dysfunction by regulation of the MMP-9/TIMP-1 balance after cerebra ischemia reperfusion in rats. J Mol Neurosci 55: 872-879, 2015.
55. Toth M, Sohail A and Fridman R: Assessment of gelatinases (MMP-2 and MMP-9) by gelatin zymography. Methods Mol Biol 878: 121-135, 2012.

56. Dong H, Diao H, Zhao Y, Xu H, Pei S, Gao J, Wang J, Hussain T, Zhao D, Zhou X and Lin D: Overexpression of matrix metalloproteinase-9 in breast cancer cell lines remarkably increases the cell malignancy largely via activation of transforming growth factor beta/SMAD signalling. Cell Prolif 52: e12633, 2019.

57. Hongwei Y, Ruiping C, Yingyan F, Guanjun Z, Jie H, Xingyu L, Jie T, Zhenghong L, Qin G, Junfeng $H$ and Heng Z: Effect of Irbesartan on AGEs-RAGE and MMPs systems in rat type 2 diabetes myocardial-fibrosis model. Exp Biol Med (Maywood) 244: 612-620, 2019.

58. Song W and Ergul A: Type-2 diabetes-induced changes in vascular extracellular matrix gene expression: Relation to vessel size. Cardiovasc Diabetol 5: 3, 2006.

59. NishihamaK, YasumaT, Yano Y,D'Alessandro-GabazzaCN,Toda M, Hinneh JA, Tonto PB, Takeshita A, Totoki T, Mifuji-Moroka R, et al: Anti-Apoptotic activity of human matrix metalloproteinase-2 attenuates diabetes mellitus. Metabolism 82: 88-99, 2018.

60. de de Morais EF, Dantas AN, Pinheiro JC, Leite RB, Barboza CA, de Vasconcelos Gurgel BC and de Almeida Freitas R: Matrix metalloproteinase- 8 analysis in patients with periodontal disease with prediabetes or type 2 diabetes mellitus: A systematic review. Arch Oral Biol 87: 43-51, 2018

61. Zhong C, Yang J, Xu T, Xu T, Peng Y, Wang A, Wang J, Peng H, Li Q, Ju Z, et al: Serum matrix metalloproteinase-9 levels and prognosis of acute ischemic stroke. Neurology 89: 805-812, 2017.

62. Abdelnaseer MM, Elfauomy NM, Esmail EH, Kamal MM and Elsawy EH: Matrix metalloproteinase- 9 and recovery of acute ischemic stroke. J Stroke Cerebrovasc Dis 26: 733-740, 2017.

63. Fatar M, Stroick M, Steffens M, Senn E, Reuter B, Bukow S, Griebe M, Alonso A, Lichtner P, Bugert P, et al: Single-Nucleotide polymorphisms of MMP-2 gene in stroke subtypes. Cerebrovasc Dis 26: 113-119, 2008

64. Nosoudi N, Nahar-Gohad P, Sinha A, Chowdhury A, Gerard P, Carsten CG, Gray BH and Vyavahare NR: Prevention of abdominal aortic aneurysm progression by targeted inhibition of matrix metalloproteinase activity with batimastat-loaded nanoparticles. Circ Res 117: e80-e89, 2015.

65. Walz W and Cayabyab FS: Neutrophil infiltration and matrix metalloproteinase-9 in lacunar infarction. Neurochem Res 42: 2560-2565, 2017.

66. Singh T, Jayaram B and Adekoya OA: Computational approaches to matrix metalloprotease drug design. Methods Mol Biol 1579: 273-285, 2017.

67. Wu Z, Mulatibieke T, Niu M, Li B, Dai J, Ye X, He Y, Chen C, Wen $\mathrm{L}$ and $\mathrm{Hu} \mathrm{G}$ : Inhibition of matrix metalloproteinase with BB-94 protects against caerulein-induced pancreatitis via modulating neutrophil and macrophage activation. Gastroenterol Res Pract 28: 8903610, 2020.

68. Dong F, Eibach M,Bartsch JW, Dolga AM,Schlomann U,Conrad C, Schieber S, Schilling O, Biniossek ML, Culmsee C, et al: The metalloprotease-disintegrin ADAM8 contributes to temozolomide chemoresistance and enhanced invasiveness of human glioblastoma cells. Neuro Oncol 17: 1474-1485, 2015.

69. Gautam J, Banskota S, Lee H, Lee YJ, Jeon YH, Kim JA and Jeong BS: Down-Regulation of cathepsin S and matrix metalloproteinase-9 via src, a non-receptor tyrosine kinase, suppresses triple-negative breast cancer growth and metastasis. Exp Mol Med 50: 1-14, 2018.

70. Sledge GW Jr, Qulali M, Goulet R, Bone EA and Fife R: Effect of matrix metalloproteinase inhibitor batimastat on breast cancer regrowth and metastasis in athymic mice. J Natl Cancer Inst 87: 1546-1551, 1995

71. Wojtowicz-Praga S, Low J, Marshall J, Ness E, Dickson R, Barter J, Sale M, McCann P, Moore J, Cole A and Hawkins MJ: Phase I trial of a novel matrix metalloproteinase inhibitor batimastat (BB-94) in patients with advanced cancer. Invest New Drugs 14: 193-202, 1996.

72. Winer A, Adams S and Mignatti P: Matrix metalloproteinase inhibitors in cancer therapy: Turning past failures into future successes. Mol Cancer Ther 17: 1147-1155, 2018.

This work is licensed under a Creative Commons Attribution-NonCommercial-NoDerivatives 4.0 International (CC BY-NC-ND 4.0) License. 